\title{
Planejamento de
}

\section{Novos Fármacos:}

\section{Inovação e Integração}

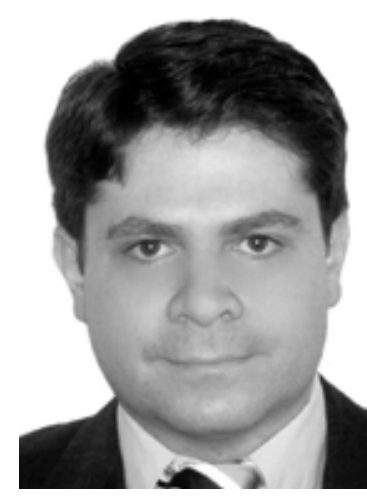

A indústria farmacêutica está constantemente voltada às inovações científicas e tecnológicas. $\mathrm{O}$ processo de descoberta e desenvolvimento de novos fármacos, que engloba várias etapas desde a pesquisa básica até o lançamento do novo medicamento no mercado farmacêutico, passando ainda pelas triagens clínicas, caracteriza-se pelos elevados níveis de investimentos em pesquisa e desenvolvimento (P\&D).

A clínica médica foi beneficiada nas últimas décadas por diversas inovações terapêuticas fantásticas, resultado do processo bem-sucedido de $\mathrm{P} \& \mathrm{D}$ de fármacos realizado pela indústria farmacêutica. A notável evolução da Química Medicinal moderna tem contribuído de forma significativa na descoberta de uma variedade de novas entidades químicas (NCEs, do inglês, New Chemical Entities) com inúmeras propriedades farmacológicas.

A descoberta de fármacos de enorme sucesso, que fazem parte da categoria dos blockbusters, termo do inglês usado para designar os medicamentos com vendas anuais superiores a US\$ 1 bilhão, é o alicerce do desenvolvimento da indústria mundial. Como exemplo, pode ser citado o fármaco com ação hipolipemiante Lípitor $^{\circledR}$ (atorvastatina), da companhia farmacêutica americana Pfizer (Figura 1). Este medicamento exerce a sua ação terapêutica através da inibição reversível da enzima humana 3-hidroxi-3-metil-glutaril coenzima A redutase (HMG-CoA redutase), controlando assim a conversão de HMG-CoA em mevalonato, uma etapa limitante na regulação da biossíntese do colesterol.

A inovação e a integração são componentes fundamentais para o crescimento e desenvolvimento da área de $\mathrm{P} \& \mathrm{D}$ de fármacos.

\author{
A inovação e a integração são \\ componentes fundamentais para o \\ crescimento e desenvolvimento da \\ área de P\&D de fármacos.
}

O Lípitor, fármaco sintético da classe das estatinas, foi introduzido na clínica médica em 1997 e logo se tornou líder de mercado. O medicamento pioneiro desta classe, um composto de origem natural denominado Mevacor $^{\circledR}$ (lovastatina), foi introduzido no mercado em 1987 pela empresa farmacêutica Merck. Pertencem ainda a classe das estatinas, os medicamentos Zocor ${ }^{\circledR}$ (sinvastatina, da Merck), Crestor ${ }^{\circledR}$ (rosuvastatina, da AstraZeneca) e Lescol $^{\circledR}$ (fluvastatina, da Novartis), todos com efeito redutor de colesterol. O exemplo do Lípitor é importante para ilustrar a competitividade no setor farmacêutico e o papel da inovação na área de $P \& D$ de fármacos. Embora já existissem outros fármacos desta mesma categoria no mercado, que a época era amplamente dominado pelo Zocor, a inovação promovida pelos enormes benefícios terapêuticos do Lípitor, foi o elemento chave para uma mudança extraordinária no panorama farmacêutico. $\mathrm{O}$ Lípitor se transformou rapidamente no medicamento de maior sucesso de vendas de toda a história da indústria farmacêutica, sendo capaz, por exemplo, de gerar novas receitas da ordem de US\$ 12,68 bilhões, somente em 2007. 

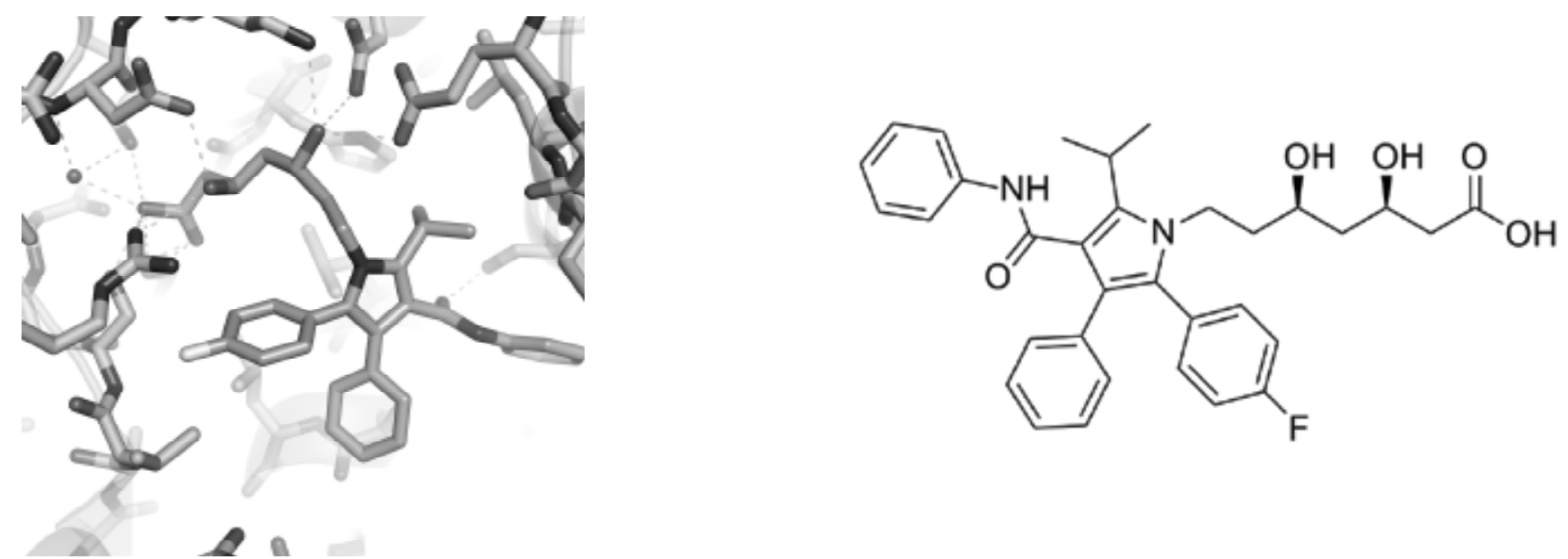

Figura 1: Interação intermolecular fármaco-receptor (à direita) e estrutura química (à esquerda) do Lípitor.

Os ensinamentos no caso do Lípitor, que se estendem a diversos outros exemplos clássicos, são muito claros, é preciso inovar para crescer, e para crescer é preciso desafiar, principalmente na área de $\mathrm{P} \& \mathrm{D}$ de novos fármacos. Prova inequívoca disso se verifica no fato de que nenhum outro tipo de indústria no mundo investe tanto em tecnologia e inovação, como a indústria farmacêutica. A Pfizer, que é a maior companhia farmacêutica de $P \& D$ de fármacos do mundo, em números atuais, alcançou US\$ 48,4 bilhões em vendas em 2007. Para atingir suas metas de crescimento e desenvolvimento, a Pfizer investiu neste mesmo ano um total de US\$ 8,1 bilhões em P\&D, aproximadamente $17 \%$ de seu faturamento bruto. Este é certamente um exemplo de gestão moderna marcada por investimentos arrojados capazes de garantir um presente de sucesso e um futuro bastante promissor no mercado mundial.

$O$ processo de $\mathrm{P} \& D$ na indústria farmacêutica está ligado a um elemento de vital importância: a inovação. $\mathrm{O}$ grande desafio de nosso país é ganhar novas fronteiras e modernizar o modelo atual de mercado, para que possamos alcançar um segundo elemento fundamental: a integração. Em todos os setores produtivos, as expectativas sobre inovação e integração devem ser administradas apropriadamente para que as melhores decisões possam ser tomadas, tornando esta tarefa menos árdua e levando a resultados mais profícuos. A dependência tecnológica nacional tornou-se quase que total em áreas estratégicas, como a saúde humana, a agropecuária e o meio ambiente, que afetam milhões de indivíduos em diversas regiões geográficas importantes. As empresas nacionais, em razão da carência de capital de risco e pessoal qualificado, não têm investido em $\mathrm{P} \& \mathrm{D}$ de fármacos, salvo algumas exceções muito recentes. Por outro lado, as multinacionais instaladas no país não se dedicam a $\mathrm{P} \& \mathrm{D}$, reservando estas atividades exclusivamente para suas matrizes nos países desenvolvidos. Outros aspectos históricos que contribuíram para este panorama foram a ausência de uma lei definida de patentes e a falta de uma política industrial clara de incentivo a estas atividades.

Em tempos modernos e olhando para o futuro, o Brasil não pode mais continuar produzindo com tecnologia importada, sem cultura de investimento de risco e sem uma agenda efetiva de aplicação em inovação. $\mathrm{O}$ panorama farmacêutico tem se alterado nos últimos anos a partir da decisão do Governo Federal de incluir os fármacos como uma das quatro áreas estratégicas e prioritárias para o país, com reflexos concretos na criação de novas políticas de investimentos para este setor, incentivando o seu crescimento e desenvolvimento. A Lei de Inovação (Lei no 10.973 de 2 de dezembro de 2004), aprovada pelo Congresso Nacional, estabelece os incentivos à inovação e à pesquisa científica e tecnológica no ambiente produtivo, gerando um ambiente favorável para o eficiente intercâmbio entre universidade e empresa, com a conseqüente transferência de tecnologias para o setor produtivo.

Os Governos Estaduais, através de suas FAPs 
(Fundações deAmparoà Pesquisa) e uma articulação eficaz junto às grandes lideranças acadêmicas e empresariais, devem estar atentos a responsabilidade que lhes cabem e assumir seu papel na criação de programas de incentivo à pesquisa e a inovação na área de medicamentos. Graças aos significativos investimentos realizados pelos órgãos de fomento do país na formação de recursos humanos, temos hoje competências estabelecidas em todas as áreas fundamentais do conhecimento, com contribuições científicas importantes e reconhecidas internacionalmente. Falta-nos, no entanto, uma maior massa crítica e, especialmente, mais foco tecnológico.

A realidade atual da indústria farmacêutica brasileira é ainda de pouca tradição em $P \& D$ de novos produtos proprietários, particularmente na área de novos medicamentos. Estabelece-se, assim, um novo paradigma sob o qual se planeja desenvolver e consolidar o setor farmacêutico no país: a tríade Empresa - Universidade - Governo. Pretende-se, desta forma, reunir as competências em inovação das universidades e dos institutos de pesquisa; a experiência, o conhecimento do mercado brasileiro, a infra-estrutura e a competência em gestão das principais indústrias farmacêuticas nacionais; e o apoio fundamental do governo com linhas de financiamento adequadas para projetos competitivos e inovadores direcionados ao setor mediante uma política clara de incentivos diretos aos investimentos em P\&D de fármacos.

O papel da universidade, da indústria e do governo é fundamental no estabelecimento de uma cultura de investimentos voltado à transferência de novas tecnologias com foco em inovação. Um caminho promissor no Estado de Goiás pode ser marcado pela integração do rico pólo farmacêutico de Anápolis, com o mestrado Profissional em Tecnologia Farmacêutica (CAPES/ MEC) organizado na tríade Universidade Católica de Goiás (UCG) - Universidade Estadual de Goiás (UEG) Centro Universitário de Anápolis (UniEVANGÉLICA). O estabelecimento de parcerias com o setor produtivo, com o governo e com outras instituições de ensino e pesquisa, será um diferencial importante para o desenvolvimento farmacêutico da região. A parceria estabelecida entre o mestrado Profissional em Tecnologia Farmacêutica e a Universidade de São Paulo, através do projeto governamental PROCAD/CAPES, é um exemplo que merece destaque por seu caráter pioneiro na conquista de novas fronteiras na área de $P \& D$ de fármacos.

$O$ futuro do setor farmacêutico nacional passa essencialmente por gestões modernas com investimentos arrojados em novas competências e tecnologias, visando o estabelecimento eficaz do binômio inovação e integração.

\section{Adriano D. Andricopulo}

Diretor da Divisão de Química Medicinal da Sociedade Brasileira de Química, coordenador do Laboratório de Química Medicinal e Computacional do Centro de Biotecnologia Molecular Estrutural da FAPESP e membro afiliado da Academia Brasileira de Ciências. 